https://www.journal-imab-bg.org

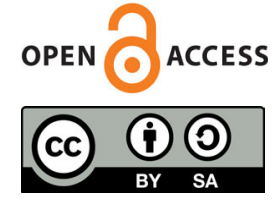

Review article

\title{
PREFORMED METAL CROWNS AS A PROSTHETIC RESTORATIONS IN PEDIATRIC DENTISTRY
}

\author{
Evgeni Dimitrov ${ }^{1}$, Milena Georgieva ${ }^{1}$, Mariana Dimova-Gabrovska ${ }^{2}$, Radosveta \\ Andreeva $^{1}$, Ani Belcheva-Krivorova ${ }^{3}$ \\ 1) Department of Pediatric dentistry, Faculty of Dental Medicine, Medical \\ University - Varna, Bulgaria \\ 2) Department of Prosthetic Dental Medicine, Faculty of Dental Medicine, \\ Medical University - Sofia, Bulgaria \\ 3) Department of Pediatric dentistry, Faculty of Dental Medicine, Medical \\ University - Plovdiv, Bulgaria
}

\begin{abstract}
:
The preformed metal crowns (PMCs) are prefabricated constructions, used for restoring a severely broken teeth, affected by multisurfice carious lesions.

The aim of the current study is to analyze and criticize the contemporary scientific conclusions related to indications, the usage methods, the advantages and disadvantages of the PMCs, used in the treatment protocol in pediatric dentistry.

The subject of the analysis is 64 english language papers, published in the period from 1966 to $2017 \mathrm{y}$.

The analysis shows that disadvantages of these restorations are related to the esthetics and previous preparation of the hard tooth tissues. The numerous advantages are related to the mechanical durability; the successful tightness concerning the non-operative sealing of caries and the prophylactic effect related to secondary caries lesion as well as the orthodontic jaw malformations, justify the usage of the PMCs in pediatric dentistry and also explain the need of scientific, clinical research in this domain.
\end{abstract}

Key words: preformed metal crowns, pediatric dentistry, prosthetic restorations

\section{BACKGROUND:}

Restorations with fixed constructions - metal crowns in the pediatric dentistry must fill the following requirements: they have to prevent the pain or discomfort of the children $[1,2,3]$; to restore the masticatory function and the stable occlusion $[4,5]$; to maintain prophylactic effect on the child's dentition [1, 2, 3, 6-11].

The present-day authors [2, 3, 12-14] consider that the main conception of the primary teeth treatment is to achieve optimal prevention by adequate dental treatment which stops the future progression of the disease as well as its complications, related with secondary infection, pain and dysfunction.

The removal of the cariogenic bacterial flora in the area of the demineralized area can be a prevention of fu- ture cavitation, but not for the carious process. According to some authors $[1,3,12,15,16]$ even on the subclinical and microscopic level the word "prevention" is not correct because a developing disease occurs. It is correct to speak about early treatment or non-operative treatment, aiming process' arrest without any operative interventions. Therefore the non-operative caries treatment should be considered as a specific and complex treatment measures, aiming the arrest of the progressive carious process on individual level - optimal control of the plaque, remineralization and a proper diet $[2,3,16,17]$.

It is known $[12-15,18]$, that for the children with high risk of caries, the number of indications for conventional fillings on primary dentition decrease due to the two terminal conditions - non-operative (preventive) treatment and the severe forms of caries with significant teeth destruction. In these cases the carious process has acute development followed by pulp inflammation, which requires endodontic treatment and preformed metal crown placement [2, 4, 6, 10, 11, 19 - 24].

According to Pitts [16], the small patients deserve the best dental treatment, preventive or operative, which will guarantee their healthy dentition in future. Other authors $[20,21]$ share their doubts concerning the restoration of the primary dentition because deciduous teeth exfoliate without any symptoms. Although there is evidence [25, 26] which strongly confront this thesis and affirm the prime significance of high quality dental treatment. The understanding $[2,3,27]$ that the choice of treatment method, as well as the restoration materials and technique of the primary teeth, depend on the individual risk of caries development, the period of the development of the dentition and the pulp condition.

The aim of the current study is to analyze and criticize the contemporary scientific results concerning the indications, methods, the advantages and disadvantages of the performed metal crowns, used in the treatment protocol in the pediatric dentistry. 
The object of the study is 64 english language journals, received by searching with the following key words: preformed metal crowns, the Hall Technique ,Restorative Dentistry Stainless steel crowns, preparation for preformed metal crowns, published in the period from 1966 to $2017 \mathrm{y}$. The received information allows the following analysis to be made, concerning the definition, indications for use, the methods for clinical work and characteristics of the preformed metal crowns as a prosthetic restoration in the pediatric dentistry.

\section{REVIEW RESULTS}

Definition: Stainless steel crowns are preformed extra-coronal restorations that are particularly useful in the restoration of large multisurface cavities and grossly broken down teeth [28]. They cover the entire clinical crown and therefore recurrent or further caries is very unlikely.

\section{Application of the preformed metal crowns as a enduring restoration in severely destroyed temporary teeth:}

The conventional method of PMCs' application requires a previous preparation of the tooth, which might be relatively hard for the general practicians during the work with the small patients [29, 30]. Although the placement of the PMCs with the purposes of minimally invasive methods of treatment, as it is in the Hall technique [3, 30 - 33] gives the opportunity these constructions to be used in the everyday dental practice of the pediatric dentists. According to $[20,29,32]$, PMCs are the most durable restorative materials in long term aspect compared to the all other filling materials, and they should be an option of choice when a restoration on primary teeth is needed, especially in children with high caries risk.

Preformed metal crowns are used for: severely decayed teeth $[5,34,35]$; primary molars with endodontic treatment $[5,23,36]$; hypoplastic or hypomineralized primary and/or permanent teeth [29, 38, 39]; children with high risk of caries in particular children treated under general anesthesia [2, 7, 40, 41]; for restorations of teeth with multisurface caries $[5,28,34,41]$; where a durable restoration may fail [29, 35, 36, 42]; fractured teeth [5, 8, 38, 41, 43]; teeth with extensive wear [1, 4, 5]; abutment for space maintainer [5, 28, 29, 38].

Careful case selection is critical to the success of the usage of the PMCs as a caries management tool. Hall PMCs are best suited to managing small to moderate Class II lesions in primary molars. A thorough clinical history and examination should be carried out and bitewing radiographs were taken. These must exclude signs and symptoms of pulpal pathology, as Hall crowns should not be placed on teeth where caries involves the pulp or there are signs/ symptoms of irreversible pulpal disease [3, 17, 43].

Methods of practical work and characteristics of the preformed metal crowns as a prosthetic restoration

A number of authors [7, 28, 34, 36] recommended placement of wooden wedges before commencing tooth preparation. These serve both to separate neighboring teeth and to reduce the risk of iatrogenic damage to the enamel of these teeth. In addition, they help to depress the gingival tissues and rubber dam [38, 44, 45]. Full et al. [22] consider that the preparation must start with the occlusal surface for that will improve access to the approximal surfaces of the tooth. Other authors $[9,38]$ recommend the preparation should start with the approximal surfaces before the occlusal. It should be reduced with $1,5 \mathrm{~mm}$., maintaining its occlusal contour $[8,15,36,38,41,45,46]$ or the tooth is out of occlusion with adequate room to fit a crown. Aproximally, tooth reduction is made through the mesial and distal contact areas, the plane of the preparation being cut at a sufficient angle to avoid the creation of ledges or steps at the gingival finishing line $[1,4,8,38,41,45$, 46]. It is necessary the preparation must be done with care to avoid damage to the neighbouring teeth [5, 38]. Lastly, the clinician should ensure that all line angles are rounded $[5,8,36,38,41,44,45,46]$.

Effective local anesthesia of the tooth under preparation is generally recommended $[4,5,15,29,36,38,41$, 45] with additional anesthesia of the palatal surfaces of upper teeth advised for some patients [22]. Even with a roottreated tooth, preparation of the mesial and distal contact areas will traumatize the local gingival tissues, and anesthesia is appropriate for these patients also [4, 22, 38]. A topical analgesic applied to the gingival area may be sufficient in these cases [4].

Preformed metal crowns for primary molars are not close fitting, except at the margin, so the preparation coronal to the gingivae does not need to be precise [37]. The most bulbous part of the primary molar tooth is at its cervical third, and it is this undercut area at the gingival margin, particularly buccally and lingually, which gives retention to the crown $[8,36]$. The mesial and distal slices should end slightly below the gingivae, on enamel [41], leaving an undercut area of intact enamel at the cervical circumference of the tooth [36]. The flexible crown wall allows it to spring into these undercut areas, thus gaining retention.Some authors [44] suggested preparing buccal and lingual walls to produce a gingivally inclined long bevel to facilitate placement of the crown [22, 37, 49]. Others [7, 28 ], however, recommended that minimal or no preparation be carried outon the buccal and lingual sides of the tooth crown unlessthere is a pronounced enamel convexity, and, if present, this should be reduced by only a limited amount [8, 17, 35, 37, 45, 47]. Duggal and Cruzon [4] recommended trying the selected crown for size before carrying out any lingual or buccal reduction. Any ledge or step present at the mesial or distal finishing line will create difficulty in seating the crown $[5,22,38,41]$, and the clinician may then trim the crown unnecessarily when it is the ledge or step that should be removed.

To obtain retention, the crown must seat subgingivallyto a depth of about $1 \mathrm{~mm}[10,38,45,46]$, and a degree of gingival blanching seems to be inevitable [5] although some authors $[36,41]$ interpreted gingival blanching as an indication that further contouring of the crown is necessary.A crown that is highin the occlusion (1-1.5 $\mathrm{mm}$ ) is acceptable, as it is considered that primary teeth 
can spontaneously adjust for this amount of occlusal discrepancy over a week or so $[4,5]$.

Many journals $[8,10,19,20,40]$ approve the high rate of success of the preformed metal crowns. Undoubtedly they provide the most durable restoration in primary dentition for the period above 40 months [7]. Although the placement of PMCs is relatively expensive and time consuming the need of replacement is extremely rare (only in $3 \%$ compared to amalgam restorations $-15 \%$ ). This fact makes the PMCs a preferred option as a restoration tool for primary teeth for a long period [50].

The classic technique for PMCs' application requires a previous preparation to be done in few easy steps: First, a restoration with GIC or compomer prior to preparation for the stainless steel crown is needed [42]. Followed by reduction of the occlusal surface by about $1.5 \mathrm{~mm}$ using a flame-shaped or tapered diamond bur. Uniform occlusal reduction will facilitate placement of the crown without interfering with the occlusion [22]. Using a fine, long, tapered diamond bur, held slightly convergent to the long-axis of the tooth, cut interproximal slices mesially and distally. The reduction should allow a probe to be passed through the contact area [48]. The buccolingual reduction should be kept to a minimum, as these surfaces are important for retention. However, the reduction may be needed when there has been significant proximal space loss or anatomical features, such as a prominent Carabelli'scusp [48]. After the preparation, an appropriate size of the crown should be chosen by measuring the mesiodistal width [49]. A trial fit is carried out before cementation. It is important that the crown should sit no more than $1 \mathrm{~mm}$ subgingivally. If there is excessive blanching of the gingival tissues, the length of the crown should be reduced and the margins should be smoothed with a whitestone [51]. Cement the crown with a GIC. If the crown has been built up before the placementof the crown, a glass ionomer luting cement may be used, otherwise a restorative GIC should be used. Care should be taken while holding the crown as it can beeasily dropped during placement. Excess cement should be wiped away and a layerof Vaseline placed around the margins while the cement is setting [7, 25, 43, 63].

Irrespective of whether the tooth to be restored is vital or non-vital, local anaesthesia should be used when placing a stainless steel crown because of the soft-tissue manipulation. Rubber dam, although sometimes difficult to place in the broken down dentition, should be used where possible [2, 3].

Application of preformed metal crowns prior management of the carious process:

When placing any restoration, the importance of achieving a high quality coronal seal is now well recognized. Furthermore, there is growing evidence that providing a good seal is maintained, the complete removal of caries is no longer necessary [12]. This enables us to minimize the amount of tooth tissue that is removed, which is of potential advantage in restoring primary molars with their thin enamel and dentine, and relatively large dental pulps [18].

When restoring occlusal lesions, adhesive materials such as GICs can usually provide an adequate seal [2, 5, 6, $20,22,24,52]$. It can, however, be extremely difficult to achieve this seal using intracoronal techniques in primary molars with large proximal lesions [21, 52, 53, 54, 55] Stainless steel crowns provide an excellent coronal seal on primary molars and as such can preventprogression of caries. The placement of stainless steel crowns, with little or no caries removal, is known as the Hall crown technique $[3,32]$.

The Hall crown technique is essentially the ultimate minimally invasive restoration as it involves the placement of stainless steel crowns, directly over carious lesions, in primary molars, with little, or no, tooth preparation or caries removal [25, 31]. Initial trials [31] in Scotland have shown that this simple technique can provide successful restorations in the medium term; indeed the technique not only outperformed conventional restorations but was preferred by the children and clinicians. This procedure can be a valid alternative, particularly when children are unable to accept conventional treatment with local anaesthetic. It is, however, not appropriate in all cases and in particular, should only be used for teeth that are symptom free and without signs or symptoms of pulpal pathology $[13,33,56]$.

Regarding the correct clinical performance, the following protocol of the Hall technique is described [3]: First step involves the selection of proper size of the crown. PMCs are tried to find one that covers the occlusal table of the tooth but does not impinge on the teeth on either side, and there is feeling of "spring back". If necessary, orthodontic separators may be placed for 3 days prior to fitting the PMC to ease placement. The PMC is not pushed through the contact points; removing it can be difficult. The smallest size of crown that will fit is chosen. The crown should not be fully seated at this point as it can be very difficult to remove for cementation [31, 57]. The second step includes the mixing and filling the crown with GIC. It is mixed to the consistency of a regular crown luting cement. The cement is placed in the PMC (it should be almost full). Care is taken to fill the crown from the base upwards and ensure that there is cement around the walls [32, 33]. Before placing the crown over the tooth, some glassionomer may be wiped on the tooth or placed in any cavitation to help to ensure a good seal [13, 25]. Placement and fixing follow. The crown is placed evenly over the tooth and engaged in the approximal contact points using finger pressure to secure its position. The child, with some encouragement, then bites down on the crown. Asking the child to bite on a cotton wool roll can help with this process. Care is taken to ensure the crown seats evenly over the tooth If necessary, the clinician may seat the PMC manually, using very firm digital pressure. If the PMC fails to fully seat, it should be removed quickly, using a large spoon excavator kept ready for this purpose [48, 56, 58]. As soon as the crown is fitted, the child is asked to open to allow the crown position to be checked, and excess GIC can be wiped away while still wet [1]. Having checked the crown is in the optimal position, and whilst the cement is still soft, the child is instructed to bite down again on the 
crown or cotton wool. It is likely that some more GIC will be extruded. The child should bite down the crown until the cement has set in order to prevent the "springback"effect of the crown, which may compromise the seal $[3,59]$. The fit of the crown is checked and excess cement removed with a hand excavator, once it has reached the gel stage. Dental floss should be used to clear the contacts of any excess. Blanching usually disappears within minutes. The occlusal discrepancy, which is minimal in the presented case, should resolve in a few weeks. The child should be praised and reassured [3, 60, 61].

The question remains as to whether there is a place for this practice when conventional techniques of proven efficiency are available. However, conventional restorations are very technique sensitive and commonly require the use of local anaesthesia and high-speed handpieces, which many young children find difficult to accept [14, 62, 63]. This technique can be a useful alternative under such circumstances. It is already being extensively used in some countries, although the paucity of long-term clinical trials $[31,33]$ prevents it from being recommended generally. Further trials are currently underway in the UK and Australasia, and the results of these studies may change recommendations for its use [2].

\section{CONCLUSION:}

Currently, the data received from the clinical trials concerning the PMCs as a restoration tool for severely decayed teeth are quite insufficient. As for disadvantages, the poor esthetics, the previous preparation of the tooth and requirement for good cooperative behaviour can be mentioned, but these disadvantages faint against their advantages [3]. Although there is evidence about their mechanical durability - average longevity of 40 months. They provide extremely good tightness when used in the non-operative sealing of caries with the Hall technique and after endodontic treatment with biological or mortal methods on primary teeth. In addition, they have anti-caries effect regarding secondary caries and also orthodontic malformations. PMCs might also be used as an abutment for space maintainers when it is necessary. All comparisons done prove that PMCs overcome all other filling materials when we talk about multisurface caries [10, 19, 64].

All these advantages of PMCs justify their usage in the pediatric dentistry and give reasons for future clinical trials concerning the effectiveness of the prosthetic treatment with PMCs in our country as of the aspect of the three biological indicators and as a tool used in the aspect of management of the carious process.

\section{REFERENCES:}

1. Fayle SA, Welbury RR, Roberts JF. British Society of Paediatric Dentistry: a policy document on management of caries in the primary dentition. Int J Paediatr Dent. 2001 Mar;11(2): 153-157. [PubMed]

2. Mahoney E, Kilpatrick $\mathrm{N}$, Hibbert S, Johnston T. 6 - Restorative paediatric dentistry. In: Handbook of Pediatric Dentistry (Fourth Edition). Edited by:Cameron AC, Widmer RP. Mosby. 16th August 2013. pp.79-102. [CrossRef]

3. Splieth $\mathrm{CH}$. Revolution in pediatric dentistry. Quintessence. 2011; pp.21-35.

4. Duggal MS, Curzon ME. Restoration of the broken down primary molar: 2. Stainless steel crowns. Dent Update. 1989 Mar;16(2):71-2, 74-5. [PubMed]

5. Duggal MS, Curzon ME, Fayle SA, Pollard MA, Robertson AJ. Restorative Techniques in Paediatric Dentistry. 1st ed. London: Martin Dunitz; 1996 May;24(3):235-236. [CrossRef]

6. AAPD. Guideline of restorative dentistry. Pediatr Dent. 2014; 37(6 15/ 16):232-243.

7. Attari N, Roberts JF. Restoration of primary teeth with crowns: a systematic review of the literature. Eur Arch Paediatr Dent. 2006 Jun;7(2):5862. [PubMed]

8. Brook AH, King NM. The role of stainless steel crowns part 1. Properties and techniques. Dent Update. 1982 Jan-Feb;9(1):25-6, 28-30. [PubMed]

9. Brook AH, King NM. The role of stainless steel crowns Part 2. Clinical applications. Dent Update. 1982 Mar;9(2):81-2, 84-5.[PubMed]

10. Memarpour M, Derafshi R, Razavi M. Comparison of microleakage from stainless steel crowns margins used with different restorative materials: An in vitro study. Dent Res $J$ (Isfahan). 2016 Jan-Feb;13(1):712.[PubMed]

11. Einwag J, Dunninger P. Stainless steel crown versus multisurface amalgam restorations: an 8-year longitudinal clinical study. Quintessence Int. 1996; 27:321-323.[PubMed]

12. Ricketts DN, Kidd EA, Innes N, Clarkson J. Complete or ultraconservative removal of decayed tissue in unfilled teeth. Cochrane Database Syst Rev. 2006 Jul 19;(3):CD003808. [PubMed]
13. Schriks MCM, Van Amerongen WE. Atraumatic perspectives of ART: psychological and physiological aspects of treatment with and without rotary instruments. Community Dent Oral Epidemiol. 2003; 31:15-20. [PubMed]

14. Tickle M, Milsom K, Kennedy A. Is it better to leave or restore carious deciduous molar teeth? A preliminary study. Prim Dent Care. 1999; 6:127-131. [PubMed]

15. Kucukyilmaz E, Savas S, Kavrik F, Yasa B, Botsali MS. Fluoride release/ recharging ability and bond strength of glass ionomer cements to sound and caries-affected dentin. Niger J Clin Pract. 2017 Feb;20(2):226-234. [PubMed]

16. Pitts NB. Background Level Care. In: Detection, Assessment, Diagnosis and Monitoring of Caries. Editor Pitts NB. Monographs in Oral Science. 2009; 21:144-148. [CrossRef]

17. Qvist V. Longevity and cariostatic effects of everyday conventional glass-ionomer and amalgam restorations in primary teeth: three-year results. J Dent Res. 1997; 76:1387-1396. [PubMed]

18. Yengopal V, Harnekar SY, Patel 
N, Siegfried N. WITHDRAWN: Dental fillings for the treatment of caries in the primary dentition. Cochrane Database Syst Rev. 2016 Oct 17;10: CD004483. [PubMed]

19. Braff MH. A comparison between stainless steel crowns and multisurface amalgams in primary molars. $J$ Dent Child 1975;42:474-478. [PubMed]

20. Chadwick B, Dummer P, Dummer F, et al. How long do fillings last? (reviewed by: Asbjorn Jokstad) Evidence Based Dent. 2002; 3:96-99. [CrosRef]

21. Chadwick BL, Evans DJ. Restoration of class II cavities in primary molar teeth with conventional and resin modified glass ionomer cements: a systematic review of the literature. Eur Arch Paediatr Dent. 2007 Mar; 8(1):14-21. [PubMed]

22. Full CA, Walker JD, Pinkham JR. Stainless steel crowns for deciduous molars. JADA. 1974 Aug;89(2): 360-364. [CrossRef]

23. Holan G, Fuks AB, Keltz N. Success rate of formocresol pulpotomy in primary molars restored with stainless steel crown vs amalgam. Pediatr Dent. 2002 May-Jun;24(3):212-6. [PubMed]

24. Hunter B. Survival of dental restorations in young patients. Community Dent Oral Epidemiol. 1985; 18(5): 285-7. [PubMed] [CrossRef]

25. Innes NP, Evans DJ. Modern approaches to caries management of the primary dentition. Br Dent J. 2013 Jun; 214(11):559-66. [PubMed]

26. Guelmann M1, Mjör IA. Materials and techniques for restoration of primary molars by pediatric dentists in Florida. Pediatr Dent. 2002 Jul-Aug; 24(4):326-31. [PubMed]

27. Maggs-Rapport FL, Treasure ET, Chadwick BL. Community dental officers' use and knowledge of restorative techniques for primary molars: an audit of two Trusts in Wales. Int $J$ Paediatr Dent. 2000; 10:133-139. [PubMed]

28. Allen WE. Stainless steel: Its use in pedodontics. Dent Clin N Amer. 1966; 1:357-363.[PubMed]

29. Clark L, Wells MH, Harris EF, Lou J. Comparison of Amount of Primary Tooth Reduction Required for Anterior and Posterior Zirconia and
Stainless Steel Crowns. Pediatr Dent. 2016 Jan-Feb;38(1):42-6. [PubMed]

30. Innes NP, Ricketts DN, Chong LY, Keightley AJ, Lamont T, Santamaria RM. Preformed crowns for decayed primary molar teeth. Cochrane Database Syst Rev. 2015 Dec 31;(12):CD005512. [PubMed]

31. Evans DJP, Southwick CAP, Foley JI, Innes NP, Pavitt SH, Hall N. The Hall technique: a pilot trial of a novel use of preformed metal crowns for managing carious primary teeth. Tuith Online. 2000; p.11. [Internet]

32. Innes NP, Evans DJ, Stirrups DR. The Hall Technique; a randomized controlled clinical trial of a novel method of managing carious primary molars in general dental practice: Acceptability of the technique and outcomes at 23 months. BMC Oral Health. 2007 Dec 20;7:18[ [PubMed]

33. Innes NP, Stirrups DR, Evans DJ, Hall N, Leggate M. A novel technique using preformed metal crowns for managing carious primary molars in general practice: a retrospective analysis. Br Dent J. 2006; 200:451454.[PubMed]

34. Seale NS. The use of stainless steel crowns. Pediatr Dent. 2002 SepOct;24(5):501-5.[PubMed]

35. Yilmaz Y, Kara NB, Yilmaz A, Sahin H. Wear and repair of stainless steel crowns. Eur J Paediatr Dent. 2011 Mar;12(1):25-30.[PubMed]

36. Myers DR. The restoration of primary molars with stainless steel crowns. ASDC J Dent Child. 1976; 43:406-409.[PubMed]

37. Staman NM, Townsend JA, Hagan JL. Observational study: discomfort following dental procedures for children. Pediatr Dent. 2013 JanFeb;35(1):52-4.[PubMed]

38. Donly KJ. Restorative dentistry for children. Dent Clin North Am. 2013 Jan;57(1):75-82.[PubMed]

39. Pinkham JR. Editorial. Intraprofessional controversies: reflections on the stainless steel crown. ASDC J Dent Child. 2001;68:292-293.[PubMed]

40. Mittal HC, Goyal A, Gauba K, Kapur A. Clinical Performance of Indirect Composite Onlays as Esthetic Alternative to Stainless Steel Crowns for Rehabilitation of a Large Carious Primary Molar. J Clin Pediatr Dent. 2016; 40(5):345-52.[PubMed]
41. More FG, Pink TC. The stainless steel crown: A clinical guide. $J$ Mich State Dent Assoc. 1973; 55:237242.[PubMed]

42. Randall RC. Preformed metal crowns for primary and permanent molar teeth: review of the literature. Pediatr Dent. 2002; 24:489-500. [PubMed]

43. Erdemci ZY, Cehreli SB, Tirali RE. Hall versus conventional stainless steel crown techniques: in vitro investigation of marginal fit and microleakage using three different luting agents. Pediatr Dent. 2014 Jul-Aug; 36(4):286-90.[PubMed]

44. Croll TP. Preformed posterior stainless steel crowns: An update. Compendium. 1999; 20:89-104. [PubMed]

45. Nash DA. The nickel-chromium crown for restoring posterior primary teeth. JADA. 1981; 102:44-49. [PubMed]

46. LighRQ. Special considerations for atypical stainless steel crown situations. Hawaii Dent J. 1987; 18:10-23. [PubMed]

47. Mink JR, Hill CJ. Modification of the stainless steel crown for primary teeth. ASDC J Dent Child. 1971; 38:197-205.[PubMed]

48. Savide NL, Caputo AA, Luke LS. The effect of tooth preparation on the retention of stainless steel crowns. ASDC J Dent Child. 1980; 46:385389. [PubMed]

49. Ramazani N, Ranjbar M. Effect of tooth preparation on microleakage of stainless steel crowns placed on primary mandibular first molars with reduced mesiodistal dimension. J Dent (Tehran). 2015 Jan;12(1):18-24.J [PubMed]

50. Innes NP, Stewart M. The Hall Technique a Simplified Method for Placing Stainless Steel Crowns on Primary Molars, may be as Successful as Traditionally Placed Crowns. J Evid Based Dent Pract. 2015 Jun;15(2):702. [PubMed]

51. Wiland L. The accurate contouring of preformed crowns. $J$ Prosthet Dent. 1973; 29:221-224. [PubMed]

52. Fejerskov O, Nyvad B, Kidd EA. Dental Caries: The Disease and its Clinical Management. Blackwell, Munksgaard. 2008;(2): 356-365. 
53. Gross LC, Griffen AL, Casamassimo PS. Compomers as class II restorations in primary molars. Pediatric Dentistry. 2001; 23:24-27.

54. Santamaria RM, Innes NP, Machiulskiene V, Evans DJ, Splieth $\mathrm{CH}$. Caries management strategies for primary molars: 1-yr randomized control trial results. J Dent Res. 2014 Nov; 93(11):1062-9.[PubMed]

55. Varughese RE, Andrews P, Sigal MJ, Azarpazhooh A. An Assessment of Direct Restorative Material Use in Posterior Teeth by American and Canadian Pediatric Dentists: I. Material Choice. Pediatr Dent. 2016 Nov 15;38(7):489-496. [PubMed]

56. Roberts JF, Attari N, Sherriff M. The survival of resin modified glass ionomer and stainless steel crown restorations in primary molars, placed in a specialist paediatric dental practice. Br Dent J. 2005; 198:427-431. [PubMed]

57. Dean AA, Bark JE, Sherriff A, Macpherson LM, Cairns A. Use of the
'Hall technique' for management of carious primary molars among Scottish general dental practitioners. Eur Arch Paediatr Dent. 2011 Jun;12(3):159-62. [PubMed]

58. Merrett MCW, Goold S, Jones CM. National Dental Inspection Programme of Scotland Report of the 2008 Survey of P1 Children. Scottish Dental Epidemiological Co-ordinating Committee. 2008.

59. Tonmukayakul U, Martin R, Clark R, Brownbill J, Manton D, Hall $\mathrm{M}$, et al. Protocol for the Hall Technique study: A trial to measure clinical effectiveness and cost-effectiveness of stainless steel crowns for dental caries restoration in primary molars in young children. Contemp Clin Trials. 2015 Sep;44:36-41[PubMed]

60. Gallagher S, O'Connell BC, O'Connell AC. Assessment of occlusion after placement of stainless steel crowns in children - a pilot study. $J$ Oral Rehabil. 2014 Oct;41(10):730-6.
[PubMed]

61. Threlfall AG, Pilkington L, Milsom KM, Blinkhorn AS, Tickle M. General dental practitioners' views on the use of stainless steel crowns to restore primary molars. Br Dent J. 2005 Oct 8;199(7):453-5. [PubMed]

62. Scottish Dental Practice Board. Annual Report 2001/2002. Edinburgh: NHS Scotland, 2002.

63. Webman M, Mulki E, Roldan $\mathrm{R}$, Arevalo O, Roberts JF, GarciaGodoy F. A Retrospective Study of the 3-Year Survival Rate of Resin-Modified Glass-Ionomer Cement Class II Restorations in Primary Molars. J Clin Pediatr Dent. 2016 Winter;40(1):8-13. [PubMed]

64. Schüler IM, Hiller M, Roloff T, Kühnisch J, Heinrich-Weltzien R. Clinical success of stainless steel crowns placed under general anaesthesia in primary molars: an observational follow up study. J Dent. 2014 Nov; 42(11):1396-403. [PubMed]

Please cite this article as: Dimitrov E, Georgieva M, Dimova-Gabrovska M, Andreeva R, Belcheva-Krivorova A. Preformed metal crowns as a prosthetic restorations in Pediatric Dentistry. J of IMAB. 2017 Jul-Sep;23(3):1627-1632. DOI: https://doi.org/10.5272/jimab.2017233.1627

Received: 27/04/2017; Published online: 05/07/2017

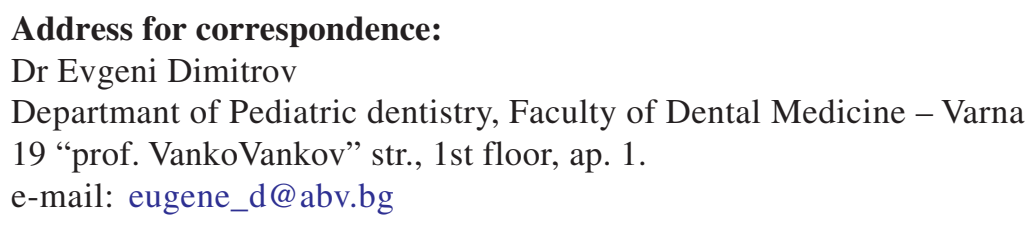

